\title{
Dietary soya isoflavones and breast carcinogenesis: a perspective from a cell-culture model
}

\author{
Lai K. Leung ${ }^{1,2}$, Yee Man Yuen ${ }^{2}$, Hau Yi Leung ${ }^{1}$ and Yun Wang ${ }^{2}$ \\ ${ }^{1}$ Food and Nutritional Sciences Programme, The Chinese University of Hong Kong, Shatin N. T., Hong Kong \\ ${ }^{2}$ Department of Biochemistry, Faculty of Medicine, The Chinese University of Hong Kong, Shatin N. T., Hong Kong
}

\begin{abstract}
Southeast Asian women have a lower incidence of breast cancer than their counterparts in the West. Epidemiological studies have indicated that soya consumption may be a contributing factor. Carcinogenesis is a process involving multiple stages. The present review attempts to fit the cellular mechanisms attributed to soya isoflavones into these different stages. Many cellculture studies have reported the growth-inhibitory effect of soya isoflavones; however, with the non-physiological concentrations employed in these studies it would be difficult to explain the protection mechanisms observed in epidemiological studies. Our laboratory has previously found that genistein inhibits cytochrome P450 (CYP)1A1 and CYP1B1. The inhibition implies that soya consumption may have the potential to prevent chemical carcinogenesis. The preferential inhibition of CYP1B1 may also block the oestrogen-initiated carcinogenesis. The antagonism of oestrogen receptor (ER) binding can affect the cell-proliferative phase, which is likely to be important in the promotion stage of breast cancer. Since our laboratory and others have indicated that genistein at physiological concentrations has no effect on the downstream activities of ER binding, the antagonism of ER is not likely to be a contributing factor in the disease prevention. Moreover, soya isoflavones cannot inhibit aromatase (CYP19), which is the enzyme responsible for oestrogen synthesis. In the present review various cellular activities altered by soya isoflavones are discussed.
\end{abstract}

\section{Soya isoflavones: Breast cancer: Cell-culture models}

\section{Introduction}

Breast cancer is one of the most common cancers in women. Asian countries have lower breast cancer incidences than the West; however, no difference in breast cancer incidence is found between Asian descendants and other women in America (Ziegler et al. 1993). These results suggest that the environment may play a part in the aetiology of breast cancer, and diet has been one of the major leads of investigation.

Epidemiological studies indicate that the consumption of some phytochemicals protects against cancer. A lower incidence of human cancers is associated with increased consumption of vegetables, fruits and beans (Kuo, 1997). The American Cancer Society (1993) has reported a lower incidence of breast cancer in the female population of Southeast Asia than those in Europe and America. One specific dietary area that epidemiologists have extensively investigated is the difference in soya consumption. Among the compounds isolated from soya beans, isoflavones have drawn the most attention for their cancer prevention activity.

Animal studies have elicited conflicting results on the cancer-protective effect of soya isoflavones. Although prepubertal administration of genistein could reduce breast cancer incidence in rats treated with 7,12-dimethylben$\mathrm{z}$ [a]anthracene (DMBA) (Hilakivi-Clarke, 2000; Lamartiniere et al. 2002), soya given after weaning appears to be ineffective (Appelt \& Reicks, 1999). In contrast, Gallo et al. (2001) have shown that genistein does not protect against DMBA-induced mammary tumour incidence or multiplicity, but it reduces the percentage of poorly differentiated tumours. In a recent study, daidzein and soya protein rather than genistein have been suggested to be the active ingredients in soya beans that reduce the multiplicity of DMBA-induced mammary tumours in rats (Constantinou et al. 2001). Nevertheless, both daidzein and genistein are effective in delaying the latency of mammary tumour

\footnotetext{
Abbreviations: AHR, aryl hydrocarbon receptor; Cdk, cyclin-dependent kinase; CYP, cytochrome P450; DMBA, 7,12-dimethylbenz[a]anthracene; ER, oestrogen receptor; ERE, oestrogen response element; JNK, c-Jun N-terminus kinase; $\mathrm{PAH}$, polycyclic aromatic hydrocarbons.

* Corresponding author: Dr Lai K. Leung, fax +852 26037732, email laikleung@yahoo.com
} 
development in a spontaneous carcinogenesis model, although the size and number of tumours are similar at the end of the experiment (Jin \& MacDonald, 2002). In contrast, genistein has been shown to increase DMBA-induced mammary tumours in oestrogen receptor (ER) $\alpha$-intact mice (Day et al. 2001), and encourages the proliferation of MCF7 and N-nitroso-N-methylurea-induced tumours respectively in athymic mice (Ju et al. 2001) and Sprague-Dawley rats (Allred et al. 2004). These reports appear to be inconsistent regarding the chemopreventive effect of genistein, but the confounding results could be caused by the phytochemical's differential actions on the initiation, promotion, and progression stages.

As illustrated in Fig. 1, breast carcinogenesis can be divided into multi-stages. During the initiation stage, various agents introduce gene mutation in the cell and no morphological changes can be observed in this stage. In the promotion-progression stage, a clonal expansion of these genetically altered cells occurs to form pre-neoplastic and neoplastic cells before growing into an invasive cell mass. Gene-environment interaction plays an important role in the aetiology of cancer, and diet is an inseparable part of this interaction.

\section{The effect of soya isoflavones in the initiation phase}

Events that lead to a permanent alteration of DNA are considered to represent the initiation phase of cancer. Longterm exposure to some environmental and dietary compounds has been linked to higher incidence of human breast cancer. Soya isoflavones are protective against cancer initiators in most investigations, while other studies indicate that their metabolites can be mutagenic.

\section{Polycyclic aromatic hydrocarbon toxicity}

Polycyclic aromatic hydrocarbons (PAH) are commonly found in our environment, and they can be isolated from diesel exhaust, barbequed meat, tobacco smoke, overheated cooking oil, etc (International Agency for Research on Cancer, 1983; Environmental Protection Agency, 1990). PAH are metabolised and transformed into DNA-attacking electrophiles in the body. The significance of these environmental toxicants in breast cancer can be inferred from the increased presence of PAH-DNA adducts in human breast tumours (Li et al. 1996).

Aryl hydrocarbon receptor (AHR) is a mediator in the transformation of procarcinogens to genotoxic moieties. After binding to a PAH, the cytosolic AHR translocates to the nucleus and dimerises with an AHR nuclear translocator. The dimerisation initiates transcription of a gene containing xenobiotic responsive elements in its promoter region (Kronenberg et al. 2000). Cytochrome P450 (CYP) 1A1 and CYP1B1 enzymes, which are responsible for the biotransformation of PAH, are downstream genes of AHR transactivation (Dertinger et al. 2000; Safe, 2001). The importance of AHR and CYP1B1 enzyme in PAH-induced carcinogenesis is implicated in results of studies in two gene-knockout mice; benzo[a]pyrene cannot induce cancer in AHR-null mice (Shimizu et al. 2000), and lower cancer incidence has been observed in DMBA-treated CYP1B1 knockout mice (Buters et al. 1999).

The inhibition of CYP1 enzymes appears to be beneficial in the prevention of DMBA-DNA adduct formation in vivo and in vitro (MacDonald et al. 2001; Kleiner et al. 2002). Polymorphisms with high activity of CYP1A1 have been shown to be a risk factor for breast cancer in AfricanAmericans (Taioli et al. 1999) and Chinese (Huang et al. 1999). CYP1B1 polymorphisms have also been associated

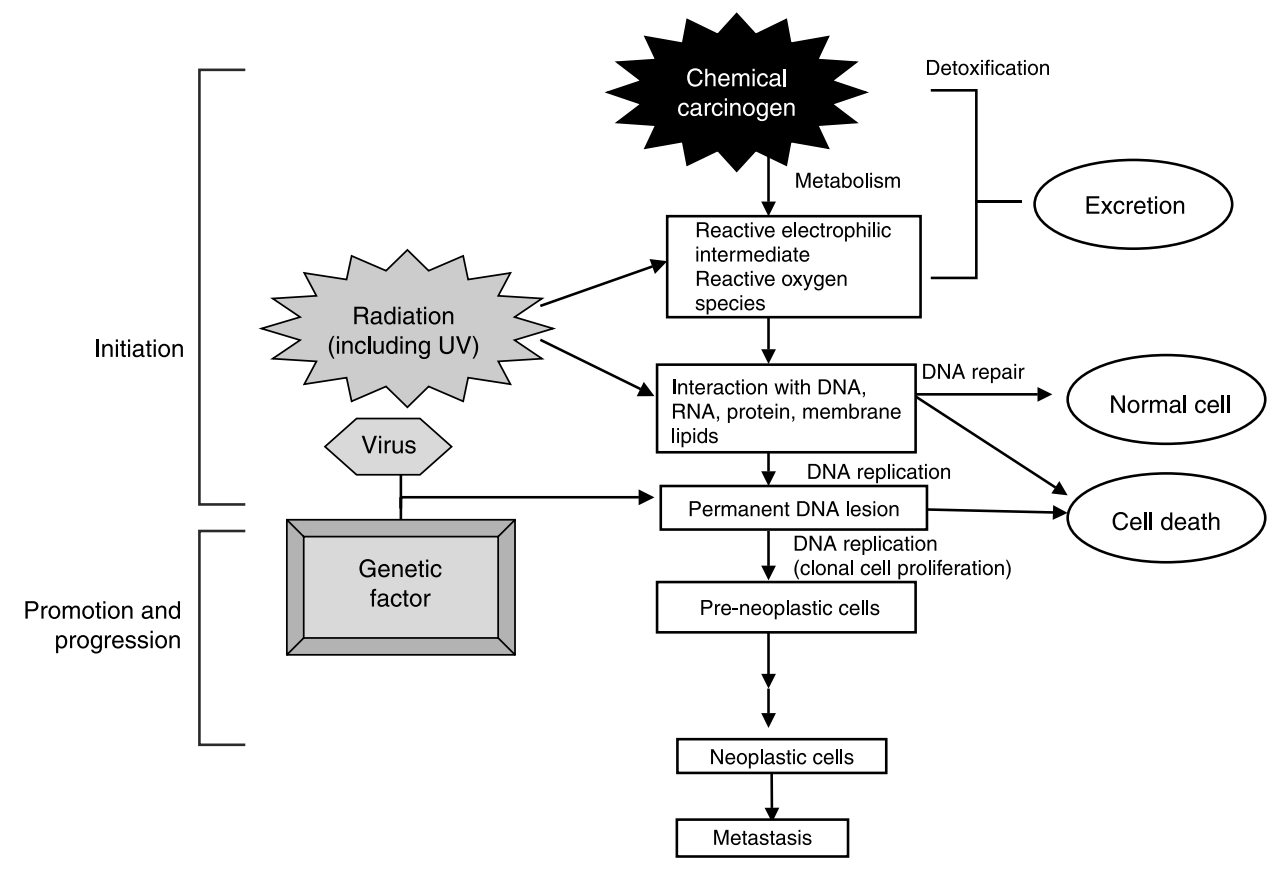

Fig. 1. Model for chemical carcinogenesis. 
with breast cancer risk in the Nurses' Health Study cohort in the USA (Huber et al. 2002) and among the Chinese women studied in Shanghai (Zheng et al. 2000).

Our in vitro model has shown that genistein reduces DMBA-DNA adduct formation and the chemopreventive mechanism may be attributed to its interruption of DMBA metabolism as shown in Fig. 2. Daidzein, on the other hand, is non-functional in this regard. Genistein down regulates CYP1A1 and 1B1 mRNA expression at $25 \mu \mathrm{mol} / 1$ through its influence on xenobiotic responsive element-dependent transcriptional control. At the enzyme level, kinetic studies have indicated that the $K_{i}$ values of CYP1A1 and 1B1 are 15.35 and $0.68 \mu \mathrm{mol} / \mathrm{l}$, respectively (Chan \& Leung, 2003). Genistein appears to preferentially inhibit CYP1B1 to CYP1A1 as denoted by the $K_{i}$ values, and the low $K_{i}$ value for CYP1B1 inhibition implicates an achievable plasma concentration through diet. CYP1B1 expression in the mammary gland has been shown to be higher than that in the liver (Horn et al. 2002), and is both inducible and constitutively expressed. This may imply that the isoflavone offers a stronger protection against $\mathrm{PAH}$-induced carcinogenesis in the mammary gland than in the liver.

A structure-inhibitory activity relationship between CYP1 enzymes and isoflavones has been described in xenobiotic-induced hepatic S9 fraction (Lee et al. 1994). The hydroxyl groups at the $\mathrm{C}^{\prime}$ and $\mathrm{C} 7$ positions of the isoflavone molecules and the phenolic group at C5 are critical for the inhibitory action of 7-ethoxyresorufin O-deethylase (Chae et al. 1992; Lee et al. 1994). As a result, daidzein that has hydroxyl groups at positions $4^{\prime}$ and 7 but lacking a C5 hydroxyl group may not be as active as genistein.

\section{Oestrogen-induced DNA damage}

Oestrogen can be hydroxylated into 2, 4, and $16 \alpha-\mathrm{OH}$ metabolites. These catechol oestrogen metabolites can further be oxidised to the quinone and semiquinone structures that are genotoxic and carcinogenic in animal models (Liehr et al. 1986; Li \& Li, 1987). Some metabolites retain oestrogenic activity, and may also generate mutagenic free radicals as well (Zhu \& Conney, 1998). As reviewed by Liehr (2000), two major CYP enzymes that are responsible

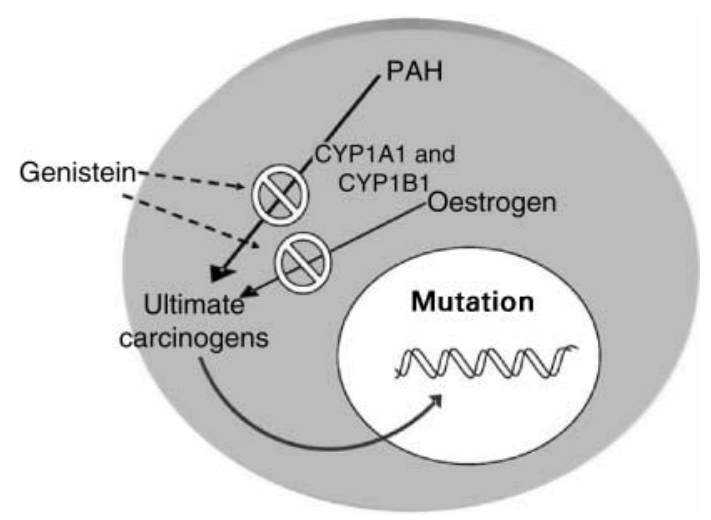

Fig. 2. Possible anti-initiation effect of genistein. $\mathrm{PAH}$, polycyclic aromatic hydrocarbons; CYP, cytochrome P450. for the hydroxylation of oestrogen are CYP1A1 (oestrogen2-hydrolase) and CYP1B1 (oestrogen-4-hydrolase). The DNA-damaging effect of oestrogen has been demonstrated in MCF-7 cells (Yared et al. 2002) and rat mammary tissues (Zhang et al. 2001). The inhibition of CYP1B1 enzymes by genistein may protect the cells from DNA damage produced by $4-\mathrm{OH}$ oestrogen (Fig. 2).

\section{DNA damage caused by soya isoflavones}

Consuming high amount of soya isoflavones may also present undesirable effects in the initiation stage of carcinogenesis. The soya isoflavone metabolites orobol and $7,3^{\prime}, 4^{\prime}-\mathrm{OH}$ isoflavone can bring about oxidative DNA damage at $10 \mu \mathrm{M}$ in human mammary epithelial MCF-10A cells (Murata et al. 2004). However, the concentration employed is above the physiological concentration.

\section{Perturbation at the promotion-progression phase}

In the multi-stage carcinogenesis model, mere occurrence of genetic alteration is not sufficient to progress to cancer. Some endogenous or exogenous stimuli must be present to facilitate clonal proliferation of the cells bearing mutated genes. The effect of soya isoflavones in this stage of carcinogenesis has been controversial.

\section{Oestrogen receptor binding}

Excessive and cumulative exposure to oestrogen has been regarded as a risk factor of breast cancer (Yager, 2000). In vivo and in vitro studies have associated increased incidence of breast cancers with oestrogen (Colditz, 1999). This cause-and-effect phenomenon has again been supported by results from a recent study in a transgenic model (Yoshidome et al. 2000).

ER is an intranuclear binding protein with a DNA-binding domain and a ligand-binding domain (Pike et al. 2000a,b). When a ligand binds onto the specific domain, the ER protein will undergo conformational changes and initiate transcription by attaching to an oestrogen response element (ERE) in the promoter region of oestrogen-sensitive genes. Recently, two subtypes of ER designated as $\alpha$ and $\beta$ have been identified, and their differences in tissue distribution and ligand affinity have been determined in the treatment of oestrogen-related diseases (Dechering et al. 2000). ER- $\alpha$ plays a crucial role in growth and differentiation of the mammary gland, but it also mediates oestrogen-induced carcinogenesis in the breast. In contrast, the role of ER- $\beta$ in breast cancer has yet to be defined. Pre-malignant breast tissue expresses more ER- $\alpha$ than normal breast tissue (Allred \& Mohsin, 2000). The ER- $\alpha$ gene, however, is mostly lost in more advanced types of breast tumour (Sheng et al. 1996). Many studies have shown that genistein is an agonist of ER, both in animal (Makela et al. 1995) and cellculture models (Wang et al. 1996; Fioravanti et al. 1998; Miodini et al. 1999). Other studies have claimed that genistein is an antagonist of ER. Kuiper et al. (1997) have expressed rat ER- $\alpha$ and $-\beta$ and found that genistein competes with $17 \beta$-oestradiol for the ligand-binding domain of ER- $\alpha$ and $-\beta$. 
Our laboratory has expressed ER- $\alpha$ and $-\beta$ in HepG 2 cells to examine the specific effect of genistein on ER. This cell line has been shown previously to be ER-negative and is useful in the evaluation of ligand-receptor interaction by expressing a specific ER isoform in the cells (Barkhem et al. 1997). We have demonstrated that genistein potentiates ER- $\alpha$ (Po et al. 2002a,b) and - $\beta$ (LS Po and LK Leung, unpublished results) transactivation with oestradiol administration. It appears that the replacement of oestradiol by genistein as the ligand of ER does not inhibit the transactivation. Since similar ERE transactivation results have been observed for ER- $\beta$, the claim that genistein is anti-oestrogenic cannot be substantiated at the cellular level. These results suggest that genistein is a potentiator rather than an antagonist in the ERinitiated nuclear event. In fact, the findings that genistein is oestrogenic at concentrations from $0 \cdot 1$ to $50 \mu \mathrm{M}$ in the presence or absence of $0.1 \mathrm{nM}$-oestradiol have also been reported by Kuiper et al. (1998) and Le Bail et al. (1998). These results suggest that the receptor-binding replacement of oestrogen by genistein cannot halt the ERE-transactivating events. In fact, genistein alone may initiate the ER-ERE complex formation (Miodini et al. 1999). The complex has been verified to be active from the transcriptions of its downstream oestrogen responsive genes, including PS2 and cathepsin D (Miodini et al. 1999).

The interaction of oestradiol and ER can be multifaceted. Hall et al. (2001) describe at least four known oestradiolinitiated signalling pathways. Two of these pathways require the transactivation of ERE whereas the others are ERE-independent. The transcriptional binding sites, Ap-1 (Paech et al. 1997), Sp-1 (Batistuzzo de Medeiros et al. 1997), raloxifene response element (Yang et al. 1996a,b) and genes containing the antioxidant response element (Montano \& Katzenellenbogen, 1997) are all responsive to oestrogen administration. Although genistein is not an effective antagonist of oestradiol on the classical EREdependent pathways, the possibility that genistein antagonised the ERE-independent signalling pathways cannot be totally ruled out. On the other hand, genistein may selectively generate an activation function-2 surface of ER- $\beta$ that recruits co-regulators for the repression and activation of transcription (An et al. 2001). Considering the influences on some non-nuclear events of ER, it is still possible that genistein can counteract the downstream events of oestrogen through modulating processes other than those dictated by ERE.

\section{Oestrogen synthesis and degradation}

Oestrogen can be synthesised from cholesterol in several steps, with CYP 19 (aromatase) catalysing the rate-limiting reaction. Polymorphisms in the CYP19 gene have been associated with breast cancer risk (Lee et al. 2003). Aromatase inhibitors have recently been shown to be promising agents in breast cancer prevention, and have fewer side effects than the ER antagonist tamoxifen (Cuzick, 2003). However, neither genistein nor daidzein is able to inhibit the synthesis of oestrogen in MCF-7 cells expressing CYP19 (Y Wang and LK Leung, unpublished results). These soya isoflavones appear not to act by perturbing oestrogen biosynthesis.
Oestrogen can be inactivated by sulfotransferase and sulfatase. Genistein and equol are mixed inhibitors of hepatic oestrogen sulfotransferase within the physiological concentration range $(0.5$ and $0.4 \mu \mathrm{M})$ (Harris et al. 2004).

\section{Programmed cell death}

Apoptosis is an important process in cancer development and therapy as reviewed by Lowe \& Lin (2000). Compounds inducing apoptosis can affect cancer initiation, progression and metastasis. Bcl-2 was the first protein shown to be antiapoptotic (Reed, 1994). Subsequently, proteins that share structural homology with Bcl-2 have been described and characterised. $\mathrm{Bcl}-\mathrm{X}$ is one of the $\mathrm{Bcl}-2$ family proteins and has two forms, the long (L) and the short (S) forms. Bcl-x(L) facilitates cell survival, whereas $\mathrm{Bcl}-\mathrm{x}(\mathrm{S})$ initiates proapoptotic signals (Reed, 1998; Reed et al. 1998; Gross et al. $1999 a, b)$. Proteins such as Bax and Bak are pro-apoptotic in many systems, and specific interaction among these proteins can determine cell survival or death (Reed, 1998; Reed et al. 1998; Gross et al. 1999a,b). The cell-death mechanism has been attributed to the release of cytochrome $c$ from mitochondria and the subsequent caspase activation (Li et al. 1997). The interactions among Bcl-2 family proteins can affect the stability of the mitochondrial membrane, which is important in confining cytochrome $\mathrm{c}$ to this organelle (Gross et al. 1999a,b). c-Jun N-terminus kinase (JNK) is activated by different stresses such as redox potential alteration, heat shock, osmotic shock, UV irradiation and cytokines. It is activated by phosphorylation carried out by the upstream mitogen-activated protein kinase. A functional JNK can phosphorylate c-Jun, JunD, ATF-2, ATFa, ELK1 and Sap-1, and its activity has been associated with apoptosis (Ip \& Davis, 1998).

Exposure to oestrogen promotes the development of breast cancer for its cell-proliferative effect (Nenci et al. 1988). One of the proposed mechanisms is in the redirection of apoptotic pathways. 17 $\beta$-Oestradiol reduces the pro-apoptotic Bak level in MCF-7 cells (Leung et al. 1998) and enhances cell survival by increasing Bcl-2 expression (Wang \& Phang, 1995). The latter is due to the direct effect of ER transactivation, because two functional ERE have been located at the $B c l-2$ gene promoter region (Perillo et al. 2000).

Studies have shown that genistein displays a proliferative effect at low concentrations (micromolar) (Wang \& Kurzer, 1997; Breinholt \& Larsen, 1998; Le Bail et al. 1998; Shao et al. 1998) and a growth-inhibitory effect at higher concentrations in MCF-7 cells (Peterson \& Barnes, 1991; So et al. 1997). These observations have been interpreted as the agonistic and antagonistic properties of genistein at low and high concentrations, respectively. However, our laboratory (Leung \& Wang, 2000; Po et al. 2002a,b) has demonstrated that apoptosis induced by genistein in MCF-7 cells is not related to the classical ER antagonistic effect. By examining the protein expression, we have found that both Bcl-2 and Bax are induced in the cultures. The induction of Bcl-2 can be a result of the oestrogenic effect of genistein. Although genistein may induce phosphorylation and inactivation of $\mathrm{Bcl}-2$ at $150 \mu \mathrm{mol} / \mathrm{l}$, the protein remains functional at the dosages at or below $50 \mu \mathrm{M}$ (Constantinou et al. 1998). An increased amount of $\mathrm{p} 53$ protein, which may be produced by 
the activity of JNK, occurs in MCF-7 cells treated with 25 and $50 \mu \mathrm{mol}$ genistein/l. Because the Bax gene promoter contains a p53-binding region (Miyashita \& Reed, 1995), the induction of Bax can be p53-dependent. Besides, Bak protein expression is up regulated while $\mathrm{Bcl}-\mathrm{x}(\mathrm{L})$ is down regulated by genistein at concentrations at which death is induced. These differential protein expressions with the exception of Bcl-2 favour programmed cell death (Po et al. $2002 a, b)$. Thus, at present, an ER-dependent mechanism of cell death induced by soya isoflavones is not known. Nevertheless, a JNK-mediated stress pathway (Leung \& Wang, 2000) may be responsible for the apoptotic response of MCF-7 cells treated with 25 and $50 \mu \mathrm{M}$-genistein as illustrated in Fig. 3. At such concentrations, JNK activation may lead to the accumulation of p53 through the MEKK1 JNK signalling pathway (Fuchs et al. 1998). In ER-negative cell lines, genistein can induce cell death in a p53independent pathway ( $\mathrm{Li}$ et al. 1999a,b) and up regulate Bax (Li et al. 1999a,b). These studies suggest that genistein can affect multiple pathways which may facilitate or counteract the cell-death process.

The biphasic proliferative effect of genistein on ERpositive breast cancer cells can be explained from the following findings. At low concentrations genistein reinforces the ERE response, which in turn encourages proliferation in ER-positive cells. Murata et al. (2004) have shown that MCF-7 cell proliferation is consistent with the binding of genistein and daidzein to the ER and ERE response by a surface plasmon resonance sensor. In addition, Chen \& Wong (2004) have shown that genistein may induce cell growth in MCF-7 cells by enhancing the insulin-like growth factor signalling pathway. As the dosage increases, genistein can activate two ER-independent pathways in the induction of cell death: one is mediated by Bcl-2 family proteins and the other can be driven by stress. Nonetheless, the minimum concentration that induces apoptosis is beyond the reach of dietary consumption.

Another mechanism for genistein inducing apoptosis in MCF-7 cells could be triggered by an increase of intracellular $\mathrm{Ca}^{2+}$ concentration. This increase of $\mathrm{Ca}^{2+}$ activates mu-calpain and caspase-12 (Sergeev, 2004).

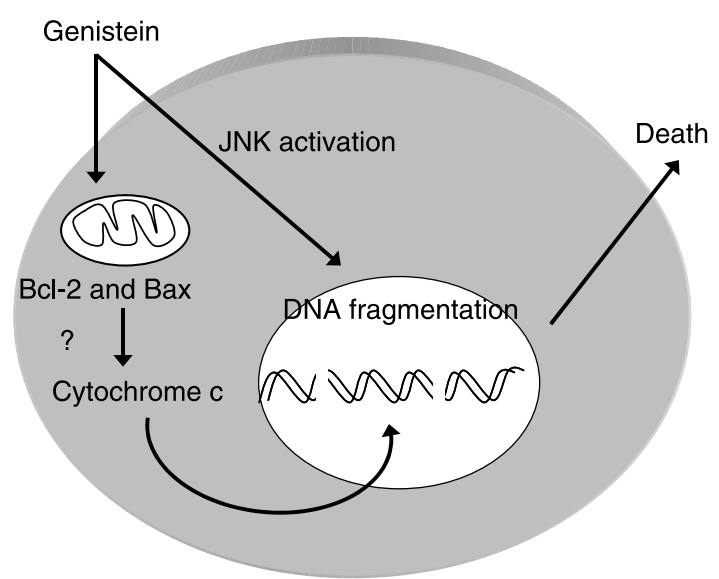

Fig. 3. Apoptosis induced by high-dose genistein. JNK, c-Jun Nterminus kinase.

\section{Cell-cycle arrest}

The cell cycle is a series of events through which cell replication has to undergo. The eukaryotic cell cycle is divided into $\mathrm{G} 1, \mathrm{~S}, \mathrm{G} 2$ and $\mathrm{M}$ phases, and there are checkpoints occurring at different phases to allow progression to the next phase. The tumour suppressor proteins $\mathrm{p} 53$ and pRb, cyclins and cyclin-dependent kinases (Cdk) have detrimental effects on the progression of the cell cycle, as reviewed by Hilakivi-Clarke et al. (2004).

In an ER-negative and HER-2-positive cell line derived from human reduction mammoplasty, $10 \mu \mathrm{M}$-genistein administration can increase cell number in the sub G0/G1 and the ratio of G0/G1:S + G2/M phases. Increases in the Cdk inhibitor p16INK4 and the Bax:Bcl-2 expression ratio are also evident (Katdare et al. 2002). Genistein has also been found to induce apoptosis in HER-2-expressing MDAMB-435 cells by up regulating Bax and p21 expression and down regulating Bcl-2 and HER-2-ERBB-2 expression ( $\mathrm{Li}$ et al. 1999a). High concentrations of genistein are required to induce apoptosis in other breast cells, such as $45 \mu \mathrm{M}$ for MCG-10F and MCF-12A cells, and $90 \mu \mathrm{M}$ for MCF10CA1a and MDA-MB-231 cells. The differential responsiveness appears to be driven by $\mathrm{p} 21$, which may also introduce G2-M cell-cycle arrest (Upadhyay et al. 2001).

Cyclin D1 forms a complex with Cdk4/6, which leads to an increased activity of $\mathrm{Cdk} 4$ and the subsequent phosphorylation of $\mathrm{Rb}$ protein. Cyclin $\mathrm{E}-\mathrm{Cdk} 2$ complex further phosphorylates $\mathrm{Rb}$ and releases E2F transcription factors. Genes inhibited by $\mathrm{Rb}$ and involved in entering the $\mathrm{S}$ phase are then induced. $\mathrm{p} 21^{\text {waf/cip } 1}$ is a CIP/KIP family protein that can inhibit the cyclin E-Cdk2 kinase activity and prevent the cell from the $\mathrm{S}$ phase entry. Effect of high genistein concentration to decrease cyclins D1 and E and induce p 21 would arrest the cell cycle at the G1 phase. At the end of the $\mathrm{G} 2$ phase, $\mathrm{Cdc} 25 \mathrm{C}$ activates $\mathrm{Cdc} 2$ by dephosphorylation and triggers the onset of mitosis. Genistein administered in pharmacological concentrations can lead to cell-cycle arrest by way of inducing $\mathrm{p} 21^{\text {waf/cip } 1}$ in MCF-7 and MDA-MB-231 cells (Shao et al. 1998), inhibition of Cdc2 activity and Cdc25C protein expression in MCF-10F cells (Frey \& Singletary, 2003). The inhibitory effect on Cdc2 and Cdc25C would stop the cell cycle at the G2-M phase. Fig. 4 summarises the cell-cycle-arresting events introduced by genistein in high dosage. However, Ju et al. (2002) have demonstrated that dietary genistein increases cyclin D in MCF-7 tumours implanted in ovariectomised rats when tamoxifen is co-administered. Increased expression of cyclin D1 and Cdk2 is also reported in MCF-7 cells treated with physiological doses of genistein (Dees et al. 1997). This may facilitate the dysregulation of cell-cycle control. This sharp contrast illustrates that one has to be cautious about the dosages given in cell-culture studies.

\section{BRCA2 expression}

High genistein $(5 \mu \mathrm{g} / \mathrm{ml})$ concentration may induce a $60 \%$ increase in BRCA2 mRNA in MDA-MB-231 and MCF-10A cells, but not in MCF-7 cells. Daidzein $(20 \mu \mathrm{g} / \mathrm{ml})$, on the other hand, does not induce any changes in BRCA2 mRNA 


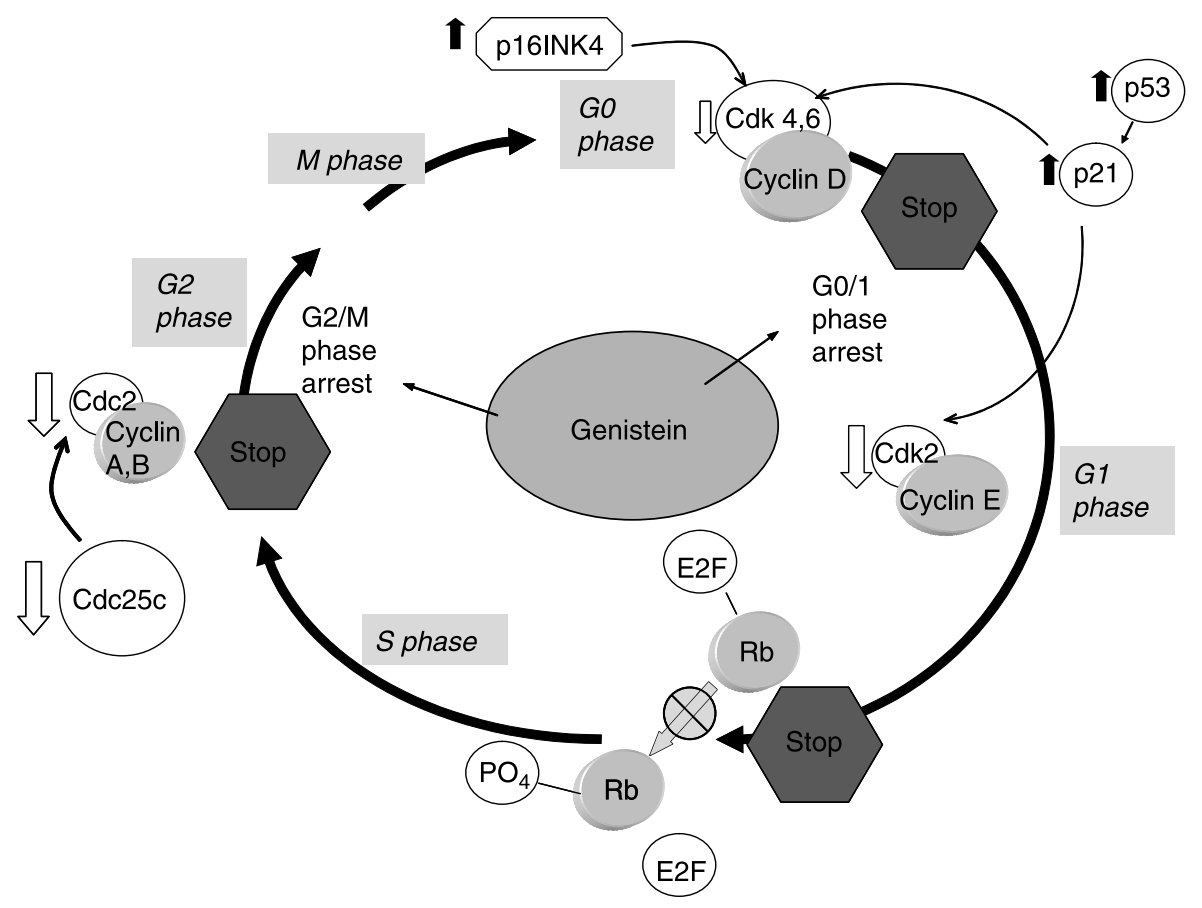

Fig. 4. Cell-cycle arrest induced by high-dose genistein.

expression. However, no BRCA2 protein increase is evident in these cell lines (Vissac-Sabatier et al. 2003). BRCA2, which is an important tumour suppressor in breast cancer, is not altered by isoflavone administration.

\section{Other active ingredients}

Soyasapogenol A and B are sapongenols found in soya beans. Either $10 \mu \mathrm{M}$-soyasapogenol A or B inhibits MDAMB-231 cell growth, while the same stimulates or displays no effect on MCF-7 cells (Rowlands et al. 2002). Soyasapogenol A appears to be oestrogenic because it induces pS2 mRNA expression and forms ER-ERE DNA complexes. Information on their bioavailability or metabolism is not yet available.

\section{Interactions between soya isoflavones and cancer therapeutic drugs}

The anti-oestrogen tamoxifen is usually prescribed as an adjuvant therapy for breast cancer patients. It reduces the proliferation of T47D breast cancer cells by inducing G1 cell-cycle arrest. The administration of low-dose genistein may reverse the cell proliferation and cell-cycle arrest (Jones et al. 2002). Similar results have also been demonstrated in an erbB-2 transgenic mouse model. These mice develop mammary tumours spontaneously, and lowdose isoflavone increases the rate and shortens the latency of tumour development (Liu et al. 2005). Unfavourable outcomes have also been reported for other therapeutic agents. In both ER-positive MCF-7 and -negative MDA-MB-231 cells, genistein minimises the apoptosis induced by paclitaxel and vincristine with an observed reduction in Bcl-2 phosphorylation and cyclin $\mathrm{B} 1-\mathrm{Cdc} 2$ kinase expression (Liao et al. 2004). Cells arrested in the G2/M phase under the drug treatment are also reduced by genistein. In contrast to the undesirable interactions, genistein in combination with adriamycin administration may enhance necrotic-like cell death through the deactivation of HER-2 and Akt (Satoh et al. 2003).

\section{Metastasis}

Genistein, daidzein, or glycitein at $10 \mu \mathrm{M}$ or above may inhibit MDA-MB-231 cell adhesion and migration by suppressing the secretion of urokinase-type plasminogen activator through NF- $\mathrm{\kappa B}$ and Ap-1 inactivation (Valachovicova et al. 2004).

\section{Bioavailability of soya isoflavones}

The dietary relevance of the genistein dosages in human subjects has been established over many years of research. The major soya isoflavone metabolite in women is in the glucuronide form, and the aglycone genistein only constitutes about $25 \%$ of total genistein present in plasma (Zhang et al. 2003). In a high-soyaconsuming country such as Japan, the average plasma concentration of total genistein is about $0.5 \mu \mathrm{mol} / 1$ in women (Morton et al. 2002). Supplementation may bring about $1 \mu \mathrm{mol}$ aglycone genistein/l in the plasma of human subjects (Izumi et al. 2000). However, the additive or synergistic effects of various soyabean phytochemicals has not been fully investigated, and such synergy may be sufficient to initiate some physiological changes as 
compared with those observed at high genistein concentrations.

Because a plasma concentration of genistein above $10 \mu \mathrm{M}$ is impossible to achieve from dietary intake, the hypothesised events of apoptosis and anti-oestrogenicity produced by soya isoflavones are unlikely to explain differences in breast cancer incidence between women in Western countries and Asia. Effects on CYP1 enzyme inhibition offer a more plausible explanation.

\section{Summary and conclusion}

Cellular events induced by high doses of soya isoflavones might not occur in response to dietary consumption alone. The cell model is an empirical system that has advantages as well as disadvantages over other model systems. It may over-simplify the actual function, but it is valuable in identifying the mechanisms involved. Studies have demonstrated that soya consumption is inversely associated with the risk of breast cancer; however, the mechanism is still controversial. The opposite effect at low and high concentrations of soya isoflavones on cell proliferation cannot provide a convincing explanation for the observations in epidemiological studies. Nevertheless, it is still possible that an additive or synergistic chemopreventive effect may occur among dietary compounds. Possible interactions among soya ingredients and other dietary components should be the focus of future investigations.

\section{Acknowledgements}

This project was supported by Direct Grant for Research no. 2041112 (The Chinese University of Hong Kong).

\section{References}

Allred CD, Allred KF, Ju YH, Clausen LM, Doerge DR, Schantz SL, Korol DL, Wallig MA \& Helferich WG (2004) Dietary genistein results in larger MNU-induced, oestrogen-dependent mammary tumors following ovariectomy of Sprague-Dawley rats. Carcinogenesis 25, 211-218.

Allred DC \& Mohsin SK (2000) Biological features of premalignant disease in the human breast. Journal of Mammary Gland Biology and Neoplasia 5, 351-364.

American Cancer Society (1993) Cancer Facts and Figures. Atlanta, GA: American Cancer Society.

An J, Tzagarakis-Foster C, Scharschmidt TC, Lomri N \& Leitman DC (2001) Oestrogen receptor beta-selective transcriptional activity and recruitment of coregulators by phyto-oestrogens. Journal of Biological Chemistry 276, 17808-17814.

Appelt LC \& Reicks MM (1999) Soy induces phase II enzymes but does not inhibit dimethylbenz[a]anthracene-induced carcinogenesis in female rats. Journal of Nutrition 129, 1820-1826.

Barkhem T, Andersson-Ross C, Hoglund M \& Nilsson S (1997) Characterization of the "Oestrogenicity" of tamoxifen and raloxifene in HepG2 cells: regulation of gene expression from an ERE controlled reporter vector versus regulation of the endogenous SHBG and PS2 genes. Journal of Steroid Biochemistry and Molecular Biology 62, 53-64.

Batistuzzo de Medeiros SR, Krey G, Hihi AK \& Wahli W (1997) Functional interactions between the estrogen receptor and the transcription activator $\mathrm{Sp} 1$ regulate the estrogen-dependent transcriptional activity of the vitellogenin A1 io promoter. Journal of Biological Chemistry 272, 18250-18260.

Breinholt V \& Larsen JC (1998) Detection of weak oestrogenic flavonoids using a recombinant yeast strain and a modified MCF7 cell proliferation assay. Chemical Research in Toxicology 11, 622-629.

Buters JT, Sakai S, Richter T, Pineau T, Alexander DL, Savas U, Doehmer J, Ward JM, Jefcoate CR \& Gonzalez FJ (1999) Cytochrome P450 CYP1B1 determines susceptibility to 7, 12dimethylbenz[a]anthracene-induced lymphomas. Proceedings of the National Academy of Sciences USA 96, 1977-1982.

Chae YH, Ho DK, Cassady JM, Cook VM, Marcus CB \& Baird WM (1992) Effects of synthetic and naturally occurring flavonoids on metabolic activation of benzo[a]pyrene in hamster embryo cell cultures. Chemico-biological Interactions 82, $181-193$.

Chan HY \& Leung LK (2003) A potential protective mechanism of soya isoflavones against 7,12-dimethylbenz[a]anthracene tumour initiation. British Journal of Nutrition 90, 457-465.

Chen WF \& Wong MS (2004) Genistein enhances insulin-like growth factor signaling pathway in human breast cancer (MCF7) cells. Journal of Clinical Endocrinology and Metabolism 89, $2351-2359$.

Colditz GA (1999) Hormones and breast cancer: evidence and implications for consideration of risks and benefits of hormone replacement therapy. Journal of Women's Health 8, 347-357.

Constantinou AI, Kamath N \& Murley JS (1998) Genistein inactivates bcl-2, delays the G2/M phase of the cell cycle, and induces apoptosis of human breast adenocarcinoma MCF-7 cells. European Journal of Cancer 34, 1927-1934.

Constantinou AI, Lantvit D, Hawthorne M, Xu X, van Breemen RB \& Pezzuto JM (2001) Chemopreventive effects of soy protein and purified soy isoflavones on DMBA-induced mammary tumors in female Sprague-Dawley rats. Nutrition and Cancer 41, $75-81$.

Cuzick J (2003) Aromatase inhibitors in prevention - data from the ATAC (arimidex, tamoxifen alone or in combination) trial and the design of IBIS-II (the second International Breast Cancer Intervention Study). Recent Results in Cancer Research 163, 96-103, discussion 264-266.

Day JK, Besch-Williford C, McMann TR, Hufford MG, Lubahn DB \& MacDonald RS (2001) Dietary genistein increased DMBA-induced mammary adenocarcinoma in wild-type, but not ER alpha KO, mice. Nutrition and Cancer 39, 226-232.

Dechering K, Boersma C \& Mosselman S (2000) Oestrogen receptors alpha and beta: two receptors of a kind? Current Medicinal Chemistry 7, 561-576.

Dees C, Foster JS, Ahamed S \& Wimalasena J (1997) Dietary oestrogens stimulate human breast cells to enter the cell cycle. Environmental Health Perspectives 105, Suppl. 3, 633-636.

Dertinger SD, Lantum HB, Silverstone AE \& Gasiewicz TA (2000) Effect of 3'-methoxy-4'-nitroflavone on benzo[a]pyrene toxicity. Aryl hydrocarbon receptor-dependent and -independent mechanisms. Biochemical Pharmacology 60, 189-196.

Environmental Protection Agency (1990) Aerometric Information Retrieval System (AIRS), Data for 1985-1990. Washington, DC: Environmental Protection Agency and US Government Printing Office.

Fioravanti L, Cappelletti V, Miodini P, Ronchi E, Brivio M \& Di Fronzo G (1998) Genistein in the control of breast cancer cell growth: insights into the mechanism of action in vitro. Cancer Letters 130, 143-152.

Frey RS \& Singletary KW (2003) Genistein activates p38 mitogenactivated protein kinase, inactivates ERK1/ERK2 and decreases $\mathrm{Cdc} 25 \mathrm{C}$ expression in immortalized human mammary epithelial cells. Journal of Nutrition 133, 226-231. 
Fuchs SY, Adler V, Pincus MR \& Ronai Z (1998) MEKK1/JNK signaling stabilizes and activates p53. Proceedings of the National Academy of Sciences USA 95, 10541-10546.

Gallo D, Giacomelli S, Cantelmo F, Zannoni GF, Ferrandina G, Fruscella E, Riva A, Morazzoni P, Bombardelli E, Mancuso S \& Scambia G (2001) Chemoprevention of DMBA-induced mammary cancer in rats by dietary soy. Breast Cancer Research and Treatment 69, 153-164.

Gross A, McDonnell JM \& Korsmeyer SJ (1999a) BCL-2 family members and the mitochondria in apoptosis. Genes and Development 13, 1899-1911.

Gross A, Yin XM, Wang K, Wei MC, Jockel J, Milliman C, Erdjument-Bromage H, Tempst P \& Korsmeyer SJ (1999b) Caspase cleaved BID targets mitochondria and is required for cytochrome c release, while BCL-XL prevents this release but not tumor necrosis factor-R1/Fas death. Journal of Biological Chemistry 274, 1156-1163.

Hall JM, Couse JF \& Korach KS (2001) The multifaceted mechanisms of estradiol and oestrogen receptor signaling. Journal of Biological Chemistry 276, 36869-36872.

Harris RM, Wood DM, Bottomley L, Blagg S, Owen K, Hughes PJ, Waring RH \& Kirk CJ (2004) Phytoestrogens are potent inhibitors of oestrogen sulfation: implications for breast cancer risk and treatment. Journal of Clinical Endocrinology and Metabolism 89, 1779-1787.

Hilakivi-Clarke L (2000) Oestrogens, BRCA1, and breast cancer. Cancer Research 60, 4993-5001.

Hilakivi-Clarke L, Wang C, Kalil M, Riggins R \& Pestell RG (2004) Nutritional modulation of the cell cycle and breast cancer. Endocrine-related Cancer 11, 603-622.

Horn TL, Reichert MA, Bliss RL \& Malejka-Giganti D (2002) Modulations of P450 mRNA in liver and mammary gland and P450 activities and metabolism of oestrogen in liver by treatment of rats with indole-3-carbinol. Biochemical Pharmacology 64, 393-404.

Huang CS, Shen CY, Chang KJ, Hsu SM \& Chern HD (1999) Cytochrome P4501A1 polymorphism as a susceptibility factor for breast cancer in postmenopausal Chinese women in Taiwan. British Journal of Cancer 80, 1838-1843.

Huber JC, Schneeberger C \& Tempfer CB (2002) Genetic modeling of oestrogen metabolism as a risk factor of hormonedependent disorders. Maturitas 41, Suppl. 1, S55-S64.

International Agency for Research on Cancer (1983) Polynuclear Aromatic Compounds, Part 1. Chemical, Environmental and Experimental Data. IARC Monographs on the Evaluation of the Carcinogenic Risk of Chemicals to Humans, vol. 32. Lyon, France: International Agency for Research on Cancer.

Ip YT \& Davis RJ (1998) Signal transduction by the c-Jun Nterminal kinase (JNK) - from inflammation to development. Current Opinion in Cell Biology 10, 205-219.

Izumi T, Piskula MK, Osawa S, Obata A, Tobe K, Saito M, Kataoka S, Kubota Y \& Kikuchi M (2000) Soy isoflavone aglycones are absorbed faster and in higher amounts than their glucosides in humans. Journal of Nutrition 130, 1695-1699.

Jin Z \& MacDonald RS (2002) Soy isoflavones increase latency of spontaneous mammary tumors in mice. Journal of Nutrition 132, 3186-3190.

Jones JL, Daley BJ, Enderson BL, Zhou JR \& Karlstad MD (2002) Genistein inhibits tamoxifen effects on cell proliferation and cell cycle arrest in T47D breast cancer cells. American Surgeon $\mathbf{6 8}$, 575-577.

Ju YH, Allred CD, Allred KF, Karko KL, Doerge DR \& Helferich WG (2001) Physiological concentrations of dietary genistein dose-dependently stimulate growth of oestrogen-dependent human breast cancer (MCF-7) tumors implanted in athymic nude mice. Journal of Nutrition 131, 2957-2962.
Ju YH, Doerge DR, Allred KF, Allred CD \& Helferich WG (2002) Dietary genistein negates the inhibitory effect of tamoxifen on growth of estrogen-dependent human breast cancer (MCF-7) cells implanted in athymic mice. Cancer Research 62, 2474-2477.

Katdare M, Osborne M \& Telang NT (2002) Soy isoflavone genistein modulates cell cycle progression and induces apoptosis in HER-2/neu oncogene expressing human breast epithelial cells. International Journal of Oncology 21, 809-815.

Kleiner HE, Vulimiri SV, Reed MJ, Uberecken A \& DiGiovanni J (2002) Role of cytochrome P450 1a1 and 1b1 in the metabolic activation of 7,12-dimethylbenz[a]anthracene and the effects of naturally occurring furanocoumarins on skin tumor initiation. Chemical Research in Toxicology 15, 226-235.

Kronenberg S, Esser C \& Carlberg C (2000) An aryl hydrocarbon receptor conformation acts as the functional core of nuclear dioxin signaling. Nucleic Acids Research 28, 2286-2291.

Kuiper GG, Carlsson B, Grandien K, Enmark E, Haggblad J, Nilsson S \& Gustafsson JA (1997) Comparison of the ligand binding specificity and transcript tissue distribution of oestrogen receptors alpha and beta. Endocrinology 138, 863-870.

Kuiper GG, Lemmen JG, Carlsson B, Corton JC, Safe SH, van der Saag PT, van der Burg B \& Gustafsson JA (1998) Interaction of oestrogenic chemicals and phytoestrogens with oestrogen receptor beta. Endocrinology 139, 4252-4263.

Kuo SM (1997) Dietary flavonoid and cancer prevention: evidence and potential mechanism. Critical Reviews in Oncogenesis 8, 47-69.

Lamartiniere CA, Cotroneo MS, Fritz WA, Wang J, Mentor-Marcel R \& Elgavish A (2002) Genistein chemoprevention: timing and mechanisms of action in murine mammary and prostate. Journal of Nutrition 132, 552S-558S.

Le Bail JC, Varnat F, Nicolas JC \& Habrioux G (1998) Oestrogenic and antiproliferative activities on MCF-7 human breast cancer cells by flavonoids. Cancer Letters 130, 209-216.

Lee H, Wang HW, Su HY \& Hao NJ (1994) The structure-activity relationships of flavonoids as inhibitors of cytochrome P-450 enzymes in rat liver microsomes and the mutagenicity of 2amino-3-methyl-imidazo[4,5-f]quinoline. Mutagenesis 9, $101-106$.

Lee KM, Abel J, Ko Y, Harth V, Park WY, Seo JS, Yoo KY, Choi JY, Shin A, Ahn SH, Noh DY, Hirvonen A \& Kang D (2003) Genetic polymorphisms of cytochrome P450 19 and 1B1, alcohol use, and breast cancer risk in Korean women. British Journal of Cancer 88, 675-678.

Leung LK, Do L \& Wang TT (1998) Regulation of death promoter Bak expression by cell density and 17 beta-estradiol in MCF-7 cells. Cancer Letters 124, 47-52.

Leung LK \& Wang TT (2000) Bcl-2 is not reduced in the death of MCF-7 cells at low genistein concentration. Journal of Nutrition 130, 2922-2926.

Li D, Wang M, Dhingra K \& Hittelman WN (1996) Aromatic DNA adducts in adjacent tissues of breast cancer patients: clues to breast cancer etiology. Cancer Research 56, 287-293.

Li F, Srinivasan A, Wang Y, Armstrong RC, Tomaselli KJ \& Fritz LC (1997) Cell-specific induction of apoptosis by microinjection of cytochrome c. Bcl-xL has activity independent of cytochrome c release. Journal of Biological Chemistry 272, 30299-30305.

Li JJ \& Li SA (1987) Oestrogen carcinogenesis in Syrian hamster tissues: role of metabolism. Federation Proceedings 46, $1858-1863$.

Li Y, Bhuiyan M \& Sarkar FH (1999a) Induction of apoptosis and inhibition of c-erbB-2 in MDA-MB-435 cells by genistein. International Journal of Oncology 15, 525-533. 
Li Y, Upadhyay S, Bhuiyan M \& Sarkar FH (1999b) Induction of apoptosis in breast cancer cells MDA-MB-231 by genistein. Oncogene 18, 3166-3172.

Liao CH, Pan SL, Guh JH \& Teng CM (2004) Genistein inversely affects tubulin-binding agent-induced apoptosis in human breast cancer cells. Biochemical Pharmology 67, 2031-2208.

Liehr JG (2000) Is estradiol a genotoxic mutagenic carcinogen? Endocrine Reviews 21, 40-54.

Liehr JG, Ulubelen AA \& Strobel HW (1986) Cytochrome P-450mediated redox cycling of oestrogens. Journal of Biological Chemistry 261, 16865-16870.

Liu B, Edgerton D, Yang X, Kim A, Ordonex-Ercan D, Mason T, Alvarez K, McKimmey C, Liu N \& Thor A (2005) Low-dose dietary phytoestrogen abrogates tamoxifen-associated mammary tumor prevention. Cancer Research 65, 879-886.

Lowe SW \& Lin AW (2000) Apoptosis in cancer. Carcinogenesis 21, 485-495.

MacDonald CJ, Ciolino HP \& Yeh GC (2001) Dibenzoylmethane modulates aryl hydrocarbon receptor function and expression of cytochromes P50 1A1, 1A2, and 1B1. Cancer Research 61, 3919-3924.

Makela S, Poutanen M, Lehtimaki J, Kostian ML, Santti R \& Vihko R (1995) Oestrogen-specific 17 beta-hydroxysteroid oxidoreductase type 1 (EC. 1.1.1.62) as a possible target for the action of phytoestrogens. Proceedings of the Society for Experimental Biology and Medicine 208, 51-59.

Miodini P, Fioravanti L, Di Fronzo G \& Cappelletti V (1999) The two phyto-oestrogens genistein and quercetin exert different effects on oestrogen receptor function. British Journal of Cancer 80, $1150-1155$.

Miyashita T \& Reed JC (1995) Tumor suppressor p53 is a direct transcriptional activator of the human bax gene. Cell 80, 293-299.

Montano MM \& Katzenellenbogen BS (1997) The quinone reductase gene: a unique oestrogen receptor-regulated gene that is activated by antioestrogens. Proceedings of the National Academy of Sciences USA 94, 2581-2586.

Morton MS, Arisaka O, Miyake N, Morgan LD \& Evans BA (2002) Phyto-oestrogen concentrations in serum from Japanese men and women over forty years of age. Journal of Nutrition 132, 3168-3171.

Murata M, Midorikawa K, Koh M, Umezawa K \& Kawanishi S (2004) Genistein and daidzein induce cell proliferation and their metabolites cause oxidative DNA damage in relation to isoflavone-induced cancer of oestrogen-sensitive organs. Biochemistry 43, 2569-2577.

Nenci I, Marchetti E \& Querzoli P (1988) Commentary on human mammary preneoplasia. The oestrogen receptor-promotion hypothesis. Journal of Steroid Biochemistry 30, 105-106.

Paech K, Webb P, Kuiper GG, Nilsson S, Gustafsson J, Kushner PJ \& Scanlan TS (1997) Differential ligand activation of oestrogen receptors ERalpha and ERbeta at AP1 sites. Science 277, $1508-1510$

Perillo B, Sasso A, Abbondanza C \& Palumbo G (2000) 17betaEstradiol inhibits apoptosis in MCF-7 cells, inducing bcl-2 expression via two oestrogen-responsive elements present in the coding sequence. Molecular and Cellular Biology 20, 2890-2901.

Peterson G \& Barnes S (1991) Genistein inhibition of the growth of human breast cancer cells: independence from oestrogen receptors and the multi-drug resistance gene. Biochemical and Biophysical Research Communications 179, 661-667.

Pike AC, Brzozowski AM \& Hubbard RE (2000a) A structural biologist's view of the oestrogen receptor. Journal of Steroid Biochemistry and Molecular Biology 74, 261-268.

Pike AC, Brzozowski AM, Walton J, Hubbard RE, Bonn T, Gustafsson JA \& Carlquist M (2000b) Structural aspects of agonism and antagonism in the oestrogen receptor. Biochemical Society Transactions 28, 396-400.

Po LS, Chen ZY, Tsang DS \& Leung LK (2002a) Baicalein and genistein display differential actions on oestrogen receptor (ER) transactivation and apoptosis in MCF-7 cells. Cancer Letters 187, 33-40.

Po LS, Wang TT, Chen ZY \& Leung LK (2002b) Genisteininduced apoptosis in MCF-7 cells involves changes in Bak and Bcl-x without evidence of anti-oestrogenic effects. British Journal of Nutrition 88, 463-469.

Reed JC (1994) Bcl-2 and the regulation of programmed cell death. Journal of Cell Biology 124, 1-6.

Reed JC (1998) Dysregulation of apoptosis in cancer. Cancer Journal from Scientific American 4, Suppl. 1, S8-S14.

Reed JC, Jurgensmeier JM \& Matsuyama S (1998) Bcl-2 family proteins and mitochondria. Biochimica et Biophysica Acta 1366, 127-137.

Rowlands JC, Berhow MA \& Badger TM (2002) Oestrogenic and antiproliferative properties of soy sapogenols in human breast cancer cells in vitro. Food and Chemical Toxicology 40, $1767-1774$.

Safe S (2001) Molecular biology of the Ah receptor and its role in carcinogenesis. Toxicology Letters 120, 1-7.

Satoh H, Nishikawa K, Suzuki K, Asano R, Virgona N, Ichikawa T, Hagiwara K \& Yano T (2003) Genistein, a soy isoflavone, enhances necrotic-like cell death in a breast cancer cell treated with a chemotherapeutic agent. Research Communications in Molecular Pathology and Pharmacology 113-114, 149-158.

Sergeev IN (2004) Genistein induces Ca2 +-mediated, calpain/caspase-12-dependent apoptosis in breast cancer cells. Biochemical and Biophysical Research Communications 321, 462-467.

Shao ZM, Wu J, Shen ZZ \& Barsky SH (1998) Genistein exerts multiple suppressive effects on human breast carcinoma cells. Cancer Research 58, 4851-4857.

Sheng ZM, Marchetti A, Buttitta F, Champeme MH, Campani D, Bistocchi M, Lidereau R \& Callahan R (1996) Multiple regions of chromosome $6 \mathrm{q}$ affected by loss of heterozygosity in primary human breast carcinomas. British Journal of Cancer 73, 144-147.

Shimizu Y, Nakatsuru Y, Ichinose M, Takahashi Y, Kume H, Mimura J, Fujii-Kuriyama Y \& Ishikawa T (2000) Benzo[a]pyrene carcinogenicity is lost in mice lacking the aryl hydrocarbon receptor. Proceedings of the National Academy of Sciences USA 97, 779-782.

So FV, Guthrie N, Chambers AF \& Carroll KK (1997) Inhibition of proliferation of oestrogen receptor-positive MCF-7 human breast cancer cells by flavonoids in the presence and absence of excess oestrogen. Cancer Letters 112, 127-133.

Taioli E, Bradlow HL, Garbers SV, Sepkovic DW, Osborne MP, Trachman J, Ganguly S \& Garte SJ (1999) Role of estradiol metabolism and CYP1A1 polymorphisms in breast cancer risk. Cancer Detection and Prevention 23, 232-237.

Upadhyay S, Neburi M, Chinni SR, Alhasan S, Miller F \& Sarkar FH (2001) Differential sensitivity of normal and malignant breast epithelial cells to genistein is partly mediated by p21(WAF1). Clinical Cancer Research 7, 1782-1789.

Valachovicova T, Slivova V, Bergman H, Shuherk J \& Sliva D (2004) Soy isoflavones suppress invasiveness of breast cancer cells by the inhibition of NF-kappaB/AP-1-dependent and -independent pathyways. International Journal of Oncology 25, 1389-1395.

Vissac-Sabatier C, Bignon YJ \& Bernard-Gallon DJ (2003) Effects of the phytoestrogens genistein and daidzein on BRCA2 tumor suppressor gene expression in breast cell lines. Nutrition and Cancer 45, 247-255. 
Wang C \& Kurzer MS (1997) Phyto-oestrogen concentration determines effects on DNA synthesis in human breast cancer cells. Nutrition and Cancer 28, 236-247.

Wang TT \& Phang JM (1995) Effects of oestrogen on apoptotic pathways in human breast cancer cell line MCF-7. Cancer Research 55, 2487-2489.

Wang TT, Sathyamoorthy N \& Phang JM (1996) Molecular effects of genistein on oestrogen receptor mediated pathways. Carcinogenesis 17, 271-275.

Yager JD (2000) Endogenous oestrogens as carcinogens through metabolic activation. Journal of the National Cancer Institute. Monographs, 67-73.

Yang NN, Bryant HU, Hardikar S, Sato M, Galvin RJ, Glasebrook AL \& Termine JD (1996) Oestrogen and raloxifene stimulate transforming growth factor-beta 3 gene expression in rat bone: a potential mechanism for oestrogen- or raloxifene-mediated bone maintenance. Endocrinology 137, 2075-2084.

Yang NN, Venugopalan M, Hardikar S \& Glasebrook A (1996) Identification of an oestrogen response element activated by metabolites of 17beta-estradiol and raloxifene. Science 273, $1222-1225$.

Yared E, McMillan TJ \& Martin FL (2002) Genotoxic effects of oestrogens in breast cells detected by the micronucleus assay and the Comet assay. Mutagenesis 17, 345-352.
Yoshidome K, Shibata MA, Couldrey C, Korach KS \& Green JE (2000) Oestrogen promotes mammary tumor development in C3(1)/SV40 large T-antigen transgenic mice: paradoxical loss of oestrogen receptoralpha expression during tumor progression. Cancer Research 60, 6901-6910.

Zhang F, Swanson SM, van Breemen RB, Liu X, Yang Y, Gu C \& Bolton JL (2001) Equine oestrogen metabolite 4-hydroxyequilenin induces DNA damage in the rat mammary tissues: formation of single-strand breaks, apurinic sites, stable adducts, and oxidized bases. Chemical Research in Toxicology 14, 1654-1659.

Zhang Y, Hendrich S \& Murphy PA (2003) Glucuronides are the main isoflavone metabolites in women. Journal of Nutrition 133, 399-404.

Zheng W, Xie DW, Jin F, Cheng JR, Dai Q, Wen WQ, Shu XO \& Gao YT (2000) Genetic polymorphism of cytochrome P450-1B1 and risk of breast cancer. Cancer Epidemiology, Biomarkers and Prevention 9, 147-150.

Zhu BT \& Conney AH (1998) Functional role of oestrogen metabolism in target cells: review and perspectives. Carcinogenesis 19, 1-27.

Ziegler RG, Hoover RN, Pike MC, Hildesheim A, Nomura AM, West DW, Wu-Williams AH, Kolonel LN, Horn-Ross PL, Rosenthal JF \& Hyer MB (1993) Migration patterns and breast cancer risk in Asian-American women. Journal of the National Cancer Institute 85, 1819-1827. 